Article

\title{
Special Equipment Safety Supervision System Architecture Based on Blockchain Technology
}

\author{
Zhipeng Liang, Keping Zhou, Rugao Gao * and Kaixin Gao
}

School of Resources and Safety Engineering, Central South University, Changsha 410083, China; zpliang@csu.edu.cn (Z.L.); qq391145637@gmail.com (K.Z.); gaokaixin@csu.edu.cn (K.G.)

* Correspondence: gaorgcsu@csu.edu.cn; Tel.: +86-158-7429-0401

Received: 6 September 2020; Accepted: 17 October 2020; Published: 20 October 2020 updates

Featured Application: A new safety supervision system architecture, by introducing the permissioned blockchain technology proposed in this paper, will be applied in special equipment safety supervision of China, which will solve many safety supervision loopholes in this field. In addition, we will also try to apply the design ideas of the system to other fields that also require safety supervision; the mining industry is the most likely target.

\begin{abstract}
With the use of the traditional safety supervision system of special equipment, the job burnout of supervision participants and other supervision problems emerge endlessly, which leads to the supervision for the prevention of safety accidents being greatly weakened. In recent years, the significance of introducing new technology to improve the original supervision system for safety accident prevention has been constantly growing. In this paper, based on the current situation of China's special equipment safety supervision, we summarize several specific requirements for improving the supervision system, namely efficient accident responsibility tracing, more transparent, more efficient data sharing, and integrating more functions. On this basis, we have designed a new system architecture, by introducing the permissioned blockchain technology, which can meet all the improvement requirements and adapt to the technical features of safety supervision work. The extensibility design of the system architecture can meet the new requirements in future work. The design idea of the system architecture can not only be used in the field of special equipment, but can also be used for reference by other fields with safety supervision requirements.
\end{abstract}

Keywords: special equipment; safety supervision; blockchain technology; accident responsibility tracing; Hyperledger Fabric

\section{Introduction}

"Special equipment" is a special term defined by China, which refers to some equipment widely used in industrial production and in people's lives. In China, special equipment is classified into eight categories, including boilers, pressure vessels, pressure pipelines, elevators, lifting machinery, passenger ropeway, large-scale amusement facilities, and special motor vehicles, inside the field (factory) [1]. This equipment is characterized by high temperature, high pressure, and high speed, and poses potential danger [2]. Once an accident happens, it will cause serious casualties and huge property losses. In 2019 alone, 130 accidents related to special equipment occurred in China, resulting in 119 deaths [3]; therefore, the safety supervision of special equipment is particularly important, and is the most effective measure to prevent safety accidents. In China, special equipment is under unified supervision of the government's specialized agencies, and a supervision system involving multiple participants of supervisory agencies at all levels, primary supervisors, equipment users, and inspection agencies, has been established. The government has enacted a series of laws and regulations to keep the 
supervision system running efficiently, and try to prevent unsafe behaviors since 2003 [4]. Nonetheless, the system did not work as expected. From the statistical reports of safety accidents over the years [5-8], the safety accidents caused by supervision factors account for the largest proportion.

In the traditional supervision system, there is no effective accountability mechanism, and detailed work records cannot be obtained when tracing the accident responsibility, which often leads to unfair punishment results. In the context of China's social relations, represented by the reciprocal social network, the data-sharing mechanism and transparency mechanism established based on the connection of independent systems and databases cannot meet the requirements of practical work. With the use of this traditional supervision system, inefficient safety management, job burnout of supervision participants, and many other safety supervision problems emerge endlessly [9].

In order to address these safety supervision problems and further reduce the frequency of safety accidents of special equipment, it is necessary to establish a function to perform efficient and accurate accident responsibility tracing, and improve the transparency of supervision information and efficiency of data sharing in safety supervision systems, which means that the original supervision system needs to be upgraded. Blockchain technology provides the possibility for such upgrading, which including a distributed, unalterable, digital ledger $[10,11]$ that can record work information in multiple series of blocks. This distributed digital ledger, with query data, inherent transparency mechanism, and efficient data-sharing mechanism, meets the requirements and technical features of special equipment safety supervision.

In this paper, we conduct a comprehensive requirement analysis based on the current situation of safety supervision of special equipment, and get the specific requirements of improving the traditional safety supervision system. Driven by these requirements, we designed a new system architecture for special equipment safety supervision based on blockchain technology. Taking the particularity of industrial blockchain application and the demand for rapid development of this system into consideration, the Hyperledger Fabric, which is a permissioned blockchain platform [12], is adopted. We regard the "transaction" of blockchain as the update of information; each supervision participant enters a specific channel of the supervision system after obtaining permission, and they record their work information by updating the smart contract of the blockchain. Once the working information is recorded, it becomes unalterable. The ledger database, composed of all work information, can provide basic data for accident responsibility tracing. When these queryable data [13] are integrated with the analysis engine, fast and efficient accident responsibility tracing can be implemented. This safety supervision system with an effective accountability mechanism makes each participant treat their work carefully, and its transparency mechanism restricts the collusion between different participants in the work that requires multiple roles to participate, and the trust between different participants is also strengthened, due to the sharing mechanism of blockchain technology.

Compared with other studies, the challenges and contributions of this paper can be summarized in the following three points:

1. Different from other research in this field that focuses on safety factor analysis, this article focuses on improving the supervision efficiency by optimizing the supervision system and changing the supervision mechanism.

There are many studies focused on safety factor analysis, which is the main research direction in the field of special equipment safety. Ding Rijia [1] and Jian Zhang et al. [14-17] use a machine learning algorithm to build a risk assessment model for the identification of key safety risk factors based on a supervision perspective; however, these researches only pointed out the composition of the danger, and did not provide a feasible solution. In addition, using internet thinking to change the function and position of the government to reform the supervision mechanism of special equipment is in great demand in China today [18]. Therefore, we propose an innovative solution based on the safety supervision problems and key risk factors summarized in previous researches, which is the safety supervision system based on blockchain technology described in this paper. 
2. Taking "transaction" as "information update", we use the smart contract of blockchain to record the work information of supervision participants. In this way, we can ensure that there is sufficient and authentic data to be relied on when tracing accident responsibility.

The Hyperledger Fabric adopted in this paper is an enterprise-grade, distributed ledger platform that offers modularity and versatility for a broad set of use cases [19], such as food traceability [20-22], education and training [23], smart energy management [24,25], pharmaceutical supply chains management [26,27], and financing [28,29]. This type of blockchain offers the ability to create channels, allowing a group of participants to create a separate ledger of information update. Based on this feature, we have set up a channel for each special equipment within the scope of supervision, and all relevant working roles will enter the channel after obtaining permission. Each participant in the channel is regarded as a "peer", and the completion of each task is regarded as the process of building blocks. Each participant uploads their work information (e.g., daily information about the safety status of special equipment, inspection results from inspection agencies) through smart contracts, and the set of a lot of work information with time sequence constitutes a blockchain.

3. The expansibility of the system is considered in the design, and the overall design idea of the system architecture can be used for reference by other safety supervision fields.

Through the establishment of a special equipment safety supervision system based on blockchain, we aim to not only solve the current supervision problems, but also to reserve an expandable space for new requirements in the future work. The modular architecture of Hyperledger Fabric provides technical support for the flexible expansion. The system architecture described in this paper is also a reference model for other fields that also have urgent needs for changing the current situation of safety supervision, such as the mining industry [30-33], the hazardous chemicals industry [34,35], and aircraft maintenance [36]. The setting of multirole participation, unalterable records, and its selective sharing mechanism in the system reflects the universality of the design; therefore, the establishment process and design idea of the system architecture can be transplanted to other fields.

This paper is organized as follows: in Section 2, a comprehensive requirement analysis of the system is carried out. We analyze the characteristics of each role in the supervision system in detail, and summarize the specific requirements for improving the safety supervision system. Section 3 explain the reasons for using blockchain technology and the Hyperledger Fabric platform. Section 4 is a detailed description of the system architecture; architecture and main functions of the system are introduced. Next, in Section 5, we discuss the shortcomings of the system, and how to improve it. At the same time, some suggestions are put forward for the development and application of the system. The conclusions and description of future work are included in Section 6.

\section{Requirement Analysis}

To design an excellent system, the first step is to understand the main contents of safety supervision work of special equipment and the role setting of participants. By role analysis, we can clarify the role setting, work content, and necessity of each role in the system. Then, we need to be clear about the current supervision problems that need to be addressed, which is also the purpose of the study. By analyzing these existing supervision problems, we can summarize all the specific requirements for improving the supervision system, which serve as a guide for our subsequent design work.

\subsection{Role Analysis}

At present, China's special equipment supervision is a multirole model; each role shares the supervision work, and it aims to reduce the unsafe state of the equipment and restrict the unsafe behavior of the staff. As shown in the special equipment supervision system represented in Figure 1, it consists of four roles, including equipment users, inspection agencies, primary supervisors, and supervisory agencies. The different sets of work content of each role make each work record have corresponding 
supervision participants, which provides a basis for establishing a good accident responsibility tracing function. It is of great significance to understand the characteristics of each role for finding supervision loopholes and improving the supervision system.

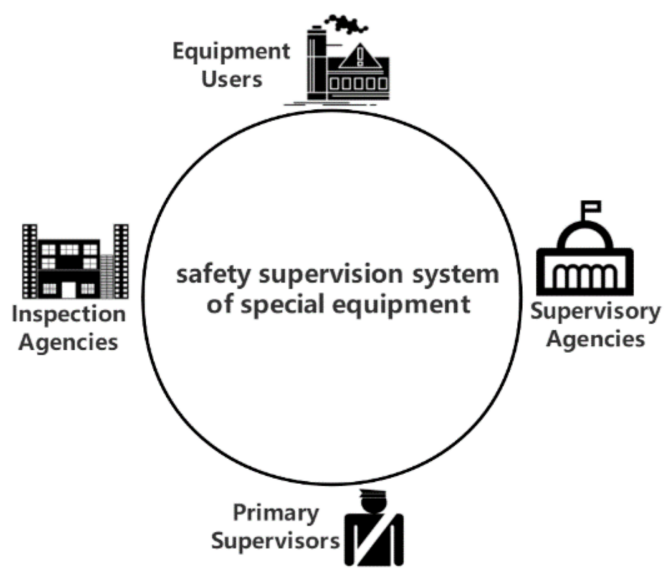

Figure 1. Role composition of special equipment safety supervision system.

\subsubsection{Equipment Users}

The users of equipment are usually some industrial enterprises, who are the most important supervision objects [37]. The safety management of an enterprise plays a vital role in preventing accidents. Every enterprise has a specific safety management plan, the most typical is that they need to record basic information about the safety status of special equipment into the supervision system regularly. Numerous analysis results based on statistical data show that safety management is the most important accident factor, and lack of commitment of safety supervision and overall safety unawareness have caused slackness in safety management of equipment users, which has resulted in an exacerbated accident rate [17].

\subsubsection{Inspection Agencies}

China's special equipment safety supervision has implemented a dual-track system that combines safety supervision with performance inspection, which means that inspection agencies play an important role in safety supervision systems. According to laws and regulations, the user of special equipment should submit a periodic inspection request to the special equipment inspection agency one month before the expiration of the validity inspection period [38]. The special equipment that has not been inspected regularly, or fails to pass the inspection, shall not be used continuously. After receiving the requirements of periodic inspection, the inspection agency should conduct safety performance inspection and energy-efficiency tests on the equipment in accordance with the requirements of safety technical specifications. Sharing inspection results with users and supervisors is another important task for inspection agencies.

\subsubsection{Primary Supervisors}

The primary supervisor is the most important role in safety supervision, in charge of the basic supervision work, and will directly face enterprises and inspection agencies. The primary supervisors will regularly go to the enterprise to check the equipment and point out the potential safety hazards, they then also need to make plans to eliminate safety hazards. In order to emphasize the importance of classified management $[39,40]$ in the safety supervision of special equipment containing complex safety technologies, each supervisor is required to be responsible only for certain types of equipment. It should be noted that, although they have regulatory rights in the supervision system, they do not participate in the accountability works after an accident. 


\subsubsection{Supervisory Agencies}

Supervisory agency means the national, or any state, county, or municipal agency, or department having the statutory authority to supervise the safety condition or inspection operation of a special equipment. The supervisory agency is usually the superior organization of the primary supervisors. It is the most important work for all supervision agencies to maintain the efficient operation of a safety supervision system of special equipment. Even more noteworthy is that the supervisory agency has the power to trace the responsibility for an accident, unlike the primary supervisors. It must be mentioned that the level of supervisory agency corresponds to the level of accidents for which it can trace responsibility in China [41]. Serious accidents are handled by state agencies, while ordinary accidents are handled by municipal agencies.

\subsection{Current Requirements}

According to the feedback from the supervision work, the most important requirement, at present, is to establish the accident responsibility tracing function. In addition, we can still find other requirements for improving the supervision system in the literature and accident reports, and this paper also tries to meet all the requirements.

We will simply enumerate all of the requirements in Table 1, and in Part 3 we will discuss whether the methods presented in this article can actually meet these requirements.

\subsubsection{Efficient Accident Responsibility Tracing}

The lack of the ability to trace accident responsibility in traditional systems is the main cause of many safety management problems and unsafe behaviors, which is also the biggest challenge in the current supervision work. The most direct consequence caused by this crucial flaw is that the primary supervisors often become scapegoats after the accident [42]. Based on this situation, primary supervisors have to increase the frequency of field checks of equipment, which leads to their fatigue and inefficiency. $\mathrm{Xu}$ et al. believe that the trust crisis among various roles in the supervision system caused by unfair accident responsibility tracing is also worthy of attention [43]. In the last few years, the significance of responsibility consciousness of supervision participants for safety accident prevention has been constantly growing. Nevertheless, the reality is that the responsibility consciousness of the supervision participants is very poor due to the lack of efficient accident responsibility tracing function, resulting in many pervasive irregularities, as follows:

1. The equipment users collude with the inspection agency to conceal the safety risks of the equipment.

2. In order to reduce maintenance costs, potential safety risks are covered by equipment users in safety management.

3. The inspection agencies are slack in inspection work.

4. Corruption between the primary supervisors and those they supervise.

\subsubsection{More Efficient Data Sharing}

The management regulation of special equipment inspection agencies [44] mentions that inspection agencies should realize real-time data sharing with the supervisor, but the actual situation does not meet such regulation. As mentioned by many researchers (e.g., Wang [45]), the supervision system and the inspection system are not integrated in some provinces of China, and in other provinces, data sharing relies on independent databases, which leads to the delayed and high technical requirements of data sharing. In addition, the distrust between equipment users and inspection agencies, caused by inefficient data sharing, also deserves our attention. In practical terms, based on the current supervision system, equipment users cannot know the latest information about the inspection license of inspection agencies and the inspection technology being used, which makes them unable to fully trust the inspection results carried out by the inspection agencies. 
Table 1. Requirements for improving the safety supervision system of special equipment.

\begin{tabular}{|c|c|c|}
\hline Requirements & Related Supervision Problems & Reference Source \\
\hline $\begin{array}{l}\text { Efficient accident } \\
\text { responsibility tracing }\end{array}$ & $\begin{array}{l}\text { The primary supervisors become scapegoats after the accident; } \\
\text { The primary supervisor's fatigue and inefficiency; } \\
\text { The trust crisis among various roles in the supervision system; } \\
\text { The equipment users collude with the inspection agency to conceal safety risks } \\
\text { of the equipment; } \\
\text { Potential safety risks are covered by equipment users in safety management; } \\
\text { The inspection agencies are slack in inspection work; } \\
\text { The corruption between the primary supervisor and those they supervise }\end{array}$ & [43] \\
\hline More efficient data sharing & $\begin{array}{l}\text { Delayed and high technical requirements of data sharing } \\
\text { Equipment user's distrust about inspection results }\end{array}$ & [45] \\
\hline $\begin{array}{l}\text { More transparent supervision } \\
\text { information }\end{array}$ & $\begin{array}{l}\text { The supervision information is seriously interfered with by interpersonal } \\
\text { relationships, resulting in low supervision efficiency }\end{array}$ & [46] \\
\hline $\begin{array}{l}\text { Integrating more functions into } \\
\text { the safety supervision system }\end{array}$ & The work of license approval is inefficient & [47] \\
\hline
\end{tabular}

\subsubsection{More Transparent Supervision Information}

Based on the research on the loopholes of special equipment supervision, Ruan et al. [46] proposed that the transparency of safety supervision information in the traditional supervision mode is not enough. In the context of China's social relations, represented by the reciprocal social network, the supervision information is seriously interfered with by interpersonal relationships, resulting in low supervision efficiency. There is a strong requirement for a more transparent supervision mode to change this situation.

\subsubsection{Integrating More Functions into the Safety Supervision System}

The work of license approval is increasingly heavy, due to the rapid growth of the number of special equipment. Considering the importance of this work, Cheng [47] has put forward tougher requirements for the function expansion of the safety supervision system. It is suggested that the license approval system be integrated into the safety supervision system so that the basic information about the equipment, users, and inspection agencies in the safety supervision system can simplify the license approval work.

\section{Methods}

\subsection{Using Blockchain Technology}

The specific requirements for improving the safety supervision system of special equipment proposed in Part 2 can be summarized into four parts: efficient accident responsibility tracing, more transparency, more efficient data sharing, and integrating more functions. The methods proposed in existing research cannot meet such complex and extremely challenging requirements. Fortunately, blockchain technology, including distributed ledger technology, transparency, and sharing mechanism, provides the possibility to address these problems. Therefore, we design a new system based on the combination of permissioned blockchain technology and safety supervision work.

We can regard the "transaction" in the blockchain as the update of supervision information. When users update their work information, they are building blocks. In this way, all the work information of participants in the supervision system will be recorded in a digital ledger composed of many blocks, and this is an unalterable distributed ledger. As can be seen in Figure 2, the ledger is jointly managed by all participants and each participant has a copy of the ledger, which makes the ledger instinctively trusted by all participants. The hash pointer described in Figure 2 plays an important role in the blockchain. Once the information in one block is rewritten, its hash value will change and be disconnected from the next block, because each block contains the hash value of the previous block, which makes the supervision work data in the block unalterable. 


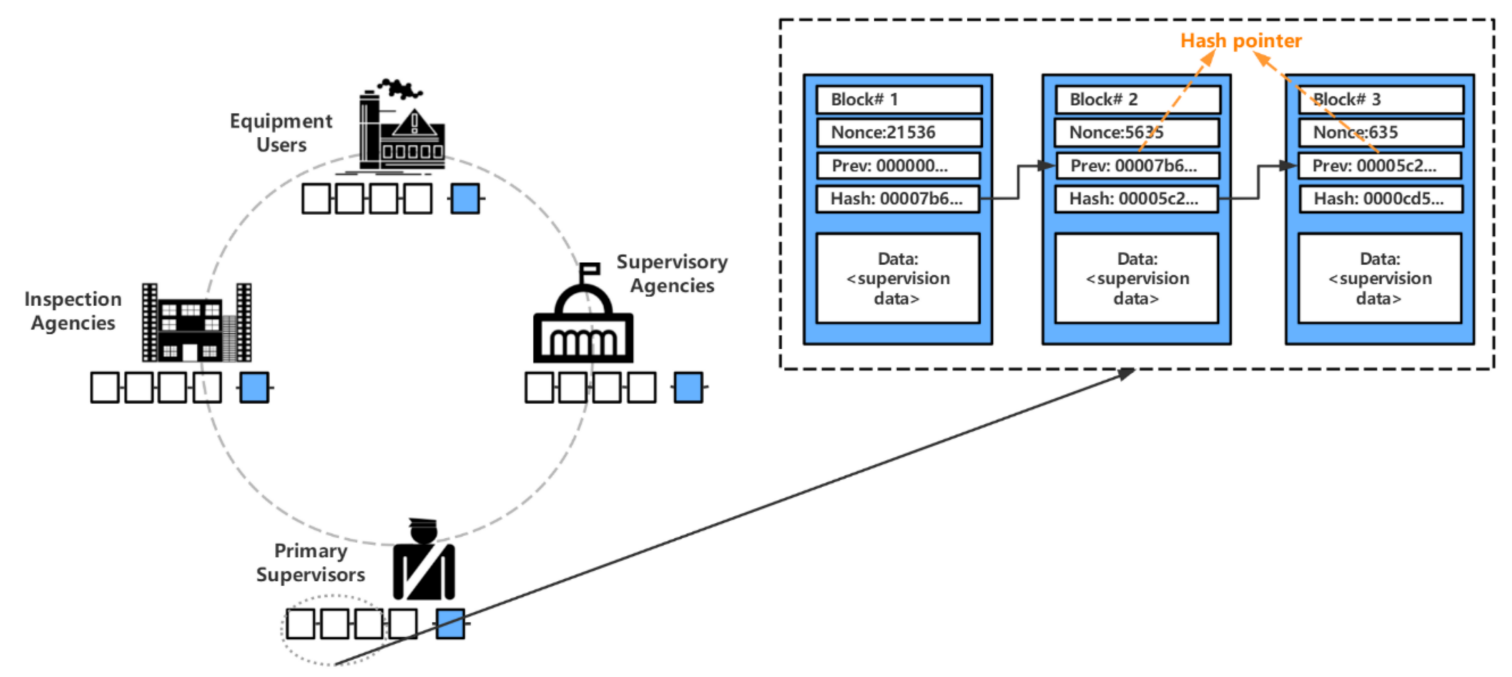

Figure 2. Distributed digital ledger of safety supervision work, composed of many blocks; the blocks are connected by hash pointer.

Therefore, the safety supervision system of special equipment based on this digital ledger can develop a fair and efficient accident responsibility tracing function, and ensure the transparency and efficient data sharing of the system.

\subsection{Blockchain Platform Selection}

Once the blockchain technology to be used is determined, the next big decision is to select the platform, which can help developers choose the right components for their application, and quickly deploy a blockchain with minimal effort [48]. Since blockchain technology has been widely used, a variety of blockchain platforms with different features have emerged. It is crucial for the success of a project to choose a suitable blockchain platform [49]. Therefore, after a systematic comparison of popular blockchain platforms, our choice is Hyperledger Fabric, which is an open and permissioned blockchain platform hosted by the Linux Foundation. Compared with other similar distributed ledger technologies, Hyperledger Fabric has some unique features [50] that are suitable for the requirements and technical features of safety supervision of special equipment, which can be seen in Table 2.

Hyperledger Fabric is an enterprise-grade, distributed ledger platform that offers modularity and versatility for a broad set of industry use cases. Rather than a permissionless system, where anyone can transact and access data, Fabric offers a permissioned, secure, and scalable platform that supports smart contracts and data privacy. This structure allows us to establish a supervision system with specific participants, and realize flexible data privatization and sharing, according to the specific data-sharing mechanism in supervision work. Fabric provides a spectrum of options to support transaction and data privacy. The channels mechanism of Hyperledger Fabric provides the possibility of keeping data private among peers. Based on this mechanism, we can set up a channel for every enterprise using special equipment to record the supervision information of all its equipment. The corresponding supervisor and inspection agency can enter this channel; the users who are not related to these equipment in the system will not participate in the work of this channel, which can keep the privacy of the data, and indeed meet the management needs of supervision work. In addition, "private data" can be used within a channel if you would like to keep the information private when updating supervision information on a shared ledger. Private data can also be shared on the basis of need-to-know, and then verified according to the hash evidence on the chain. Our blockchain network also provides an effective solution to the significant problem of collusion between equipment user and the supervisor. If the equipment user and the primary supervisor deliberately put the false data into the system, these data will have their endorsements, and they have no right to delete this information. 
Due to the traceability mechanism of the blockchain network, these evidences of collusion can be traced at any time, which effectively prevents the occurrence of collusion.

As can be seen in Table 2, the method presented here does meet all the requirements summarized in Part 2.

Table 2. The suitability between Hyperledger Fabric and safety supervision system of special equipment.

\begin{tabular}{ll}
\hline \multicolumn{1}{c}{ Features of Hyperledger Fabric } & \multicolumn{1}{c}{$\begin{array}{c}\text { Corresponding Requirements and Technical Features of } \\
\text { Safety Supervision of Special Equipment }\end{array}$} \\
\hline Permissioned and modular architecture & $\begin{array}{l}\text { Authorization for participants in supervision work, integrating } \\
\text { more functions into the safety supervision system }\end{array}$ \\
\hline $\begin{array}{l}\text { Queryable data-supporting multiple query methods, and event hooks } \\
\text { to integrate data into your preferred database or analytics engine. }\end{array}$ & Efficient accident responsibility tracing \\
\hline Lower latency of confirmation & More efficient supervision and data sharing \\
\hline Supporting rolling upgrades and asymmetric version & Expansibility, new requirements in the future \\
\hline $\begin{array}{l}\text { Open smart contract model—flexibility to support various solution and } \\
\text { data models (account model, UTXO model, structured data, } \\
\text { unstructured data, etc.) }\end{array}$ & Supporting diversified supervision information records \\
\hline $\begin{array}{l}\text { Data privacy -complete transaction isolation using "channels", or share } \\
\text { private data on a need-to-know basis using private data "collections" }\end{array}$ & $\begin{array}{l}\text { Keeping data safe, supporting the independent supervision of } \\
\text { each equipment and the classified supervision }\end{array}$ \\
\hline Multi-language smart contract support: Go, Java, Javascript & More suitable developers, lower development threshold \\
\hline \begin{tabular}{l} 
Governance and versioning of smart contracts \\
\hline
\end{tabular} & Flexible and efficient supervision information records \\
\hline
\end{tabular}

\section{Blockchain System Architecture for Safety Supervision of Special Equipment}

\subsection{System Users}

System users include equipment users, primary supervisors, inspection agencies, supervisory agencies at all levels, and third-party certification authority. All of them will use the system in their work. However, some system users will not participate in the establishment of the blockchain. Only system users whose work involves supervision information that needs to be recorded are blockchain participants. The organizations joining the Hyperledger Fabric blockchain network include enterprise using special equipment, primary supervision team, inspection agencies, and supervisory agencies at all levels. The most typical participants in a channel are 2-3 representatives of enterprise using special equipment, 2-3 primary supervisors, a representative of inspection agency, and a representative of a senior supervisory agency.

\subsection{System Design}

When we establish a safety supervision system of special equipment based on the Hyperledger Fabric blockchain, it means that the "transaction" in the blockchain will be regarded as the update of supervision information, which is completed by the smart contract (smart contracts in Hyperledger Fabric are written in chaincode), and each participant will be regarded as a "peer". As shown in Figure 3, there are many users of this system in the blockchain network, who can invoke the smart contract by mobile APP or computer programs to complete their work. It must be mentioned that Hyperledger Fabric provides us with the ability to create a "channel", which allows a group of users to establish a separate ledger of safety supervision work. This means that we can set up a "channel" for every enterprise using special equipment, and let the users who entered the supervision system with permission be divided into different "channels", so as to realize the independent supervision of every enterprise using special equipment. A channel has one, and only one, ledger; each peer in the channel maintains the same ledger, and they can copy this ledger, which is also the advantage of distributed ledger. According to the number of participants in each channel we set, there will only be 6-8 copies of each ledger. 

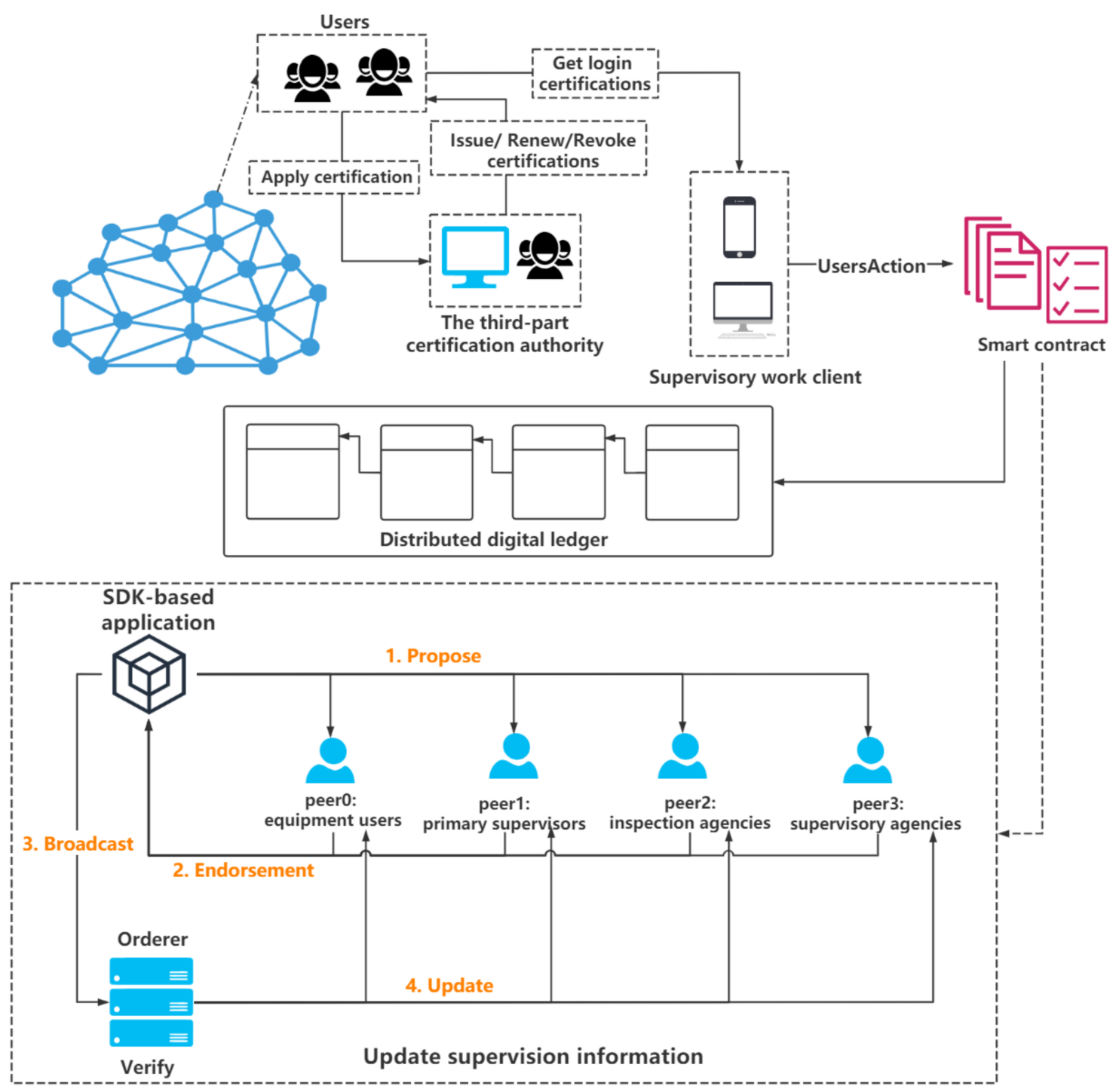

Figure 3. System architecture. SDK refers to an integrated development kit, which contains a series of application programming interfaces, used by client applications to interact with a Hyperledger Fabric blockchain network.

As can be seen in Figure 3, this is the workflow of performing ledger updates by smart contracts: At the beginning, the SDK-based application will submit the endorsement verification to the specific peer involved in the work (maybe the equipment users, inspection agencies, primary supervisors, or supervisory agencies in this project), and then the peer will return the result. After enough endorsements are collected, the SDK-based application broadcasts the update application to the orderer for ordering, packaging, and sending it to the peer, and then the update will be completed after the peer verifies the update information. In addition, it needs to be explained that the ordering service is used to provide an atomic broadcast ordering service for consumption by the peers. In this process, the client first submits transaction information to the orderer (ordering service node) through the Google Remote Procedure Call (gRPC) connection, then the orderer node that receives the request parses and checks the message, then broadcasts the message to the peers. The orderer also can maintain the consistency of the data of each node, and locally maintain the ledger (blockchain) structure for each channel. We adopted ordering service based on Raft consensus, which is provided in version 1.4.1 of Fabric. Its many advantages are why we adopted it; the Raft model can tolerate the crashes, and the system will run normally when there is a node failure, if it can ensure that more than half of 
the nodes are running normally. The Raft ordering service is easier to set up and manage than the Kafka ordering service. As has been included in the fabric community, the implementation of Raft ordering service is more convenient for developers.

The most typical data that will be input into the blockchain system are self-inspection results from equipment users and third-party inspection results issued by inspection agencies. Here, we take Table 3 as an example to describe the typical data. As can be seen, the size of a record is usually less than $20 \mathrm{~kb}$, and the default block file size is around $70 \mathrm{~kb}$ when storing the ledger.

Table 3. The typical third-party inspection results of traction and positive drive lift.

\begin{tabular}{cll}
\hline Inspection Items & Results & \multicolumn{1}{c}{ Remarks } \\
\hline Technical files & Pass/Fail & Describe the reason, if Fail \\
Operator certificates & Pass/Fail & Describe the reason, if Fail \\
Infrastructure & Pass/Fail & Describe the reason, if Fail \\
Cabs & Pass/Fail & Describe the reason, if Fail \\
Cages & Pass/Fail & Describe the reason, if Fail \\
Metal structures & Pass/Fail & Describe the reason, if Fail \\
Wire ropes and pulleys & Pass/Fail & Describe the reason, if Fail \\
Transmission systems & Pass/Fail & Describe the reason, if Fail \\
Electrical system & Pass/Fail & Describe the reason, if Fail \\
Safety system & Pass/Fail & Describe the reason, if Fail \\
Load tests & Pass/Fail & Describe the reason, if Fail \\
\hline
\end{tabular}

\subsection{System Function}

The Hyperledger Fabric SDK allows applications to manage the lifecycle of Hyperledger channels and user chaincode, it also provides a means to execute user chaincode, query blocks, and transactions on the channel, and monitor events on the channel, and it is also an interface to certification authority. We need to develop two types of client applications to meet our requirements based on Hyperledger Fabric SDK; one is called "supervisory work client", and the other is called "certification client". The users of the supervisory work client include supervisors, equipment users, and inspection agencies, and there are multiple user login interfaces in the client to adapt to different user identities. The requirements of users who use the supervision work client mainly include recording safety management information, recording inspection information, recording sampling check information, and accident responsibility tracing, as described below.

The certificate client application is for use by the third-party certification authority. It helps Hyperledger blockchain to generate certificates and keys, and configure and manage identity certificate issues in Hyperledger. Before entering the designated blockchain network, each user must first apply to the third-party certification authority for identity registration. The third-party certification authority can issue login certificates (ECERTS), renew certificates, or revoke certificates based on the actual needs and technical management policies of the system.

\subsubsection{Recording Safety Management Information}

Enterprises using special equipment need to conduct regular safety inspections and identify potential safety hazards, which is the most important part of their safety management. According to the laws and regulations, equipment users should conduct self-inspection at least once a month. With this function, users can record the safety management information representing their responsibilities in the digital ledger in time. Primary supervisors will participate in this work as a peer. In the supervision channel of some equipment that needs special attention, supervisory agencies will also be invited to participate in this work. 


\subsubsection{Recording Inspection Information}

The frequency of third-party inspections varies for different types of equipment, but it is clear that most equipment is inspected at least once a year. The completion of a third-party inspection must generate two records in the blockchain system. Special equipment users submit a third-party inspection application through the client, and then the inspection agency can accept the inspection task through their client, so the first record is written into the system. After that, the inspection agency completes the inspection according to the technical regulations, and initiates the second "transaction" in the blockchain system to record the inspection results. After obtaining the confirmation of the equipment user, this "transaction" is completed, and all the testing information has been recorded in the system. With this function, equipment users, primary supervisors, and supervisory agencies can obtain timely inspection results of the equipment and see its potential risks. If the inspection results show that there is a serious risk to the equipment, the supervisory agencies will immediately make a decision to stop using the equipment.

\subsubsection{Recording Sampling Check Information}

The sampling check of special equipment is the main work of primary supervisors. According to the Chinese Special Equipment Safety Supervision Regulations [51], the update for recording sampling check information in the system also requires the verification of the equipment users, which means that the equipment users must accept the check result, or this work cannot be completed. The implementation of this function is risky for primary supervisors. If they make any mistakes, they will be queried during the accident responsibility tracing.

\subsubsection{Accident Responsibility Tracing}

The accident responsibility tracing is the core function of this system, which will only be opened to supervisory agencies after an accident. With this function, supervisory agencies can determine who is responsible for an accident by querying the data in the digital ledger. Hyperledger Fabric provides many query methods (including keyed queries, range queries, and JSON queries) and allows data to be integrated into the preferred database or analytics engine, which ensures the efficient implementation of this function.

\section{Discussion}

According to the description of the blockchain system architecture for special equipment safety supervision, it can be seen that this proposed system architecture can well meet the requirements of improving the traditional system, and the current supervision problems are expected to be solved after the system is actually applied. For the analysis of effectiveness and efficiency of the proposed architecture, it is necessary to take the ability to complete the task objectives, the feasibility of system application and promotion, the expansibility of the system function, and the shortcomings of system into consideration.

\subsection{The Ability to Complete the Task Objectives}

As described in Section 4, regarding the implementation process of various system functions, including recording safety management information, recording inspection information, recording sampling check information, and accident responsibility tracing, it can be ensured that the design of the system architecture fully considers the characteristics of various tasks in the supervision work, and users can use the system to achieve their task objectives. In addition, we also simply tested a network channel whose nodes and configuration are consistent with our description in Section 4.1. Within $180 \mathrm{~s}$, the network can successfully complete 800 transactions with $100 \%$ availability; however, more reliable performance test data need to be obtained in the actual application of the system, in view of the complexity of special equipment supervision network. 


\subsection{The Feasibility of System Application and Promotion}

As for the application and promotion of the system in practical work, considering that many countries, including China, implement hierarchical supervision, it is recommended to first apply it in a small area (e.g., a city), and then gradually expand the scope of application. In this process, the formulation of regulations for the promotion, user training, and the iterative upgrade of the system also needs to be taken seriously.

\subsection{The Expansibility of the System Function}

Obviously, if the system is popularized and applied well, new requirements will be born with it, and it is inevitable to expand the functions of the system. Taking the technical features of the system architecture into consideration, some feasible extensions are recommended to be implemented first:

1. Add the information, before the equipment is put into use, to the traceability system, including the information of primary material supply, product processing, transportation, and installation.

2. For elevator, amusement facilities, and other public service equipment, public supervision interface should be developed so that the public can query the maintenance information and safe condition of the equipment through QR code.

\subsection{The Shortcomings and Solutions}

Blockchain technology plays an important role in the system, but there is still something to be improved. Although the security, reliability, and efficiency of blockchain technology improve the feasibility of its implementation, its low tolerance mechanism for errors restricts the flexibility of user operation. The possible solutions include standardizing operating procedures, establishing a mechanism of cancelling wrong operations (deleting world state data), and adding fault-tolerant algorithms to the blockchain network. The support of Hyperledger Fabric for multiple data structures keeps the flexibility of data, but the efficiency of data mining in such a huge digital ledger will be affected. It is very important for the success of the system to optimize data mining methods and strengthen data standardization with meeting the requirements.

In summary, it is basically certain that the proposed system architecture can meet the requirements for effectiveness and efficiency of the special equipment safety supervision system.

\section{Conclusions}

The number of special equipment in China is increasing year by year, and the related safety supervision work is becoming heavier and heavier. In the context of China's social relations, represented by the reciprocal social network, the traditional safety supervision system of special equipment has exposed many drawbacks, resulting in endless loopholes in safety supervision. Considering the high frequency of safety accidents in special equipment, and the huge casualties and property losses caused by it, it is necessary to improve the safety supervision system. Aiming to find out the specific requirements for improving the safety supervision system, we conducted a requirement analysis based on the current supervision situation and the suggestions in numerous literature and accident reports. As a result, the current specific requirements can be summarized into four parts: efficient accident responsibility tracing, more transparency, more efficient data sharing, and integrating more functions.

For a long time, many researchers have failed to put forward feasible solutions to meet these requirements, so that the situation of safety supervision could not be changed, but blockchain technology provides different possibilities. Many unique features of blockchain technology, such as the inherent transparency mechanism and data-sharing mechanism, just meet our requirements. Therefore, we propose to design a special equipment safety supervision system based on blockchain technology. As described in this paper, our basic idea is to build the system on a distributed digital ledger with unlimited extension, and treat "transactions" of the blockchain as information updates, so we can record all supervision information by updating the ledger. In order to adapt to the technical 
features of special equipment safety supervision work and simplify the development process of the system, the Hyperledger Fabric blockchain platform will be adopted. From the system architecture and the description of system functions, we can see that the system can maintain an efficient and safe implementation mechanism, and various supervision work can be well completed in it.

Although the system has so many advantages and excellent feasibility, some data standardization and operation process optimization design still need to be improved. The development and testing of the system are a long process. In the future, we will cooperate with more supervision authorities and blockchain developers to apply the system to practice as soon as possible. In addition, we will also try to apply the design ideas of the system to other fields that also require safety supervision; the mining industry is the most likely target.

Author Contributions: Conceptualization: R.G. and Z.L.; methodology: Z.L.; software: Z.L.; validation: K.Z., K.G., and R.G.; formal analysis: R.G.; investigation: Z.L.; resources: R.G.; data curation: Z.L.; writing-original draft preparation: Z.L.; writing-review and editing: R.G.; visualization: K.G.; supervision: K.Z.; project administration: K.Z.; funding acquisition: K.Z. and Z.L. All authors have read and agreed to the published version of the manuscript.

Funding: This research was funded by Fundamental Research Funds Project for the Central South University, grant number 1053320182278. The APC was funded by Central South University.

Acknowledgments: The authors are grateful to SafeMine Co., Ltd. for its technical support.

Conflicts of Interest: The authors declare no conflict of interest.

\section{References}

1. Ding, R.; Zhang, Y. Analysis on safety risk and structure relations of special equipment based on the perspective of supervision. In Proceedings of the 2017 International Conference on Service Systems and Service Management, Dalian, China, 16-18 June 2017; IEEE: Piscataway, NJ, USA, 2017.

2. Lan, Q.; Xiao, Y.; Wang, P. The Current Situation and Development Countermeasure for China Special Equipment Safety Supervision. J. US-China Public Adm. 2017, 14, 46-56.

3. State Administration for Market Regulation. The Report about Safety Situation of Special Equipment in China in 2019; State Administration for Market Regulation: Beijing, China, 2020. Available online: http: //www.samr.gov.cn/tzsbj/tzgg/zjwh/202004/t20200416_314295.html (accessed on 16 April 2020).

4. Jiang, S. Study on Safety Classification Supervision of Special Equipment Users Based on Risk. Ph.D. Thesis, Department of Management Science and Engineering, China University of Mining and Technology, Beijing, China, 2013.

5. State Administration for Market Regulation. The Report about Safety Situation of Special Equipment in China in 2018; State Administration for Market Regulation: Beijing, China, 2019. Available online: http: //www.samr.gov.cn/tzsbj/gzdt/201904/t20190404_292592.html (accessed on 19 November 2019).

6. State Administration for Market Regulation. The Report about Safety Situation of Special Equipment in China in 2017; State Administration for Market Regulation: Beijing, China, 2018. Available online: https: //www.sohu.com/a/229317479_468648 (accessed on 24 April 2018).

7. State Administration for Market Regulation. The Report about Safety Situation of Special Equipment in China in 2016; State Administration for Market Regulation: Beijing, China, 2017. Available online: http: //www.samr.gov.cn/tzsbj/tzgg/zjwh/201704/P020190216455423723930.doc (accessed on 10 April 2017).

8. State Administration for Market Regulation. The Report about Safety Situation of Special Equipment in China in 2015; State Administration for Market Regulation: Beijing, China, 2016. Available online: http: //www.samr.gov.cn/tzsbj/tzgg/zjwh/201604/t20160405_283556.html (accessed on 5 April 2016).

9. Shao, L. Research on Safety Supervision of Special Equipment in China. Master's Thesis, Department of Public Administration, Jilin University, Changchun, China, 2014.

10. Ølnes, S.; Ubacht, J.; Janssen, M. Blockchain in government: Benefits and implications of distributed ledger technology for information sharing. Gov. Inf. Q. 2017, 34, 355-364. [CrossRef]

11. Natarajan, H.; Krause, S.; Gradstein, H. Distributed Ledger Technology and Blockchain; World Bank Group: Washington, DC, USA, 2017; Note No. 1. Available online: https:/elibrary.worldbank.org/doi/abs/10.1596/ 29053 (accessed on 15 March 2018). 
12. Mao, D.; Wang, F.; Hao, Z.; Li, H. Credit Evaluation System Based on Blockchain for Multiple Stakeholders in the Food Supply Chain. Int. J. Environ. Res. Public Health 2018, 15, 1627. [CrossRef] [PubMed]

13. Adriaan, L.; Shila, D.M. Blockchain for Distributed Systems Security: Private Blockchain Configurations for Improved IoT Security; John Wiley \& Sons: Hoboken, NJ, USA, 2019; pp. 253-274.

14. Zhang, G.-M.; Qiu, C.-L.; Li, X.-D.; Zhu, W. The Risk Assessment Model of Special Equipment Based on F-AHP and ANN. In Proceedings of the 2008 Fourth International Conference on Natural Computation, Jinan, China, 18-20 October 2008; IEEE: Piscataway, NJ, USA, 2008.

15. Men, Z.; Zhang, Y. Risk assessment of special equipment. J. Saf. Sci. Technol. 2006, 2, 92-94.

16. Zeng, Z.; Luo, Y.; Yang, Y.; Zhang, Y. Identification and analysis of special equipment's use-related key risk factors suitable for supervision. J. China. Saf. Sci. 2014, 24, 157-163.

17. Zhang, J.; Li, H.; Liang, X. The Analysis of Special Equipment Accident Factor Based on Rough Set. In Proceedings of the 21st International Conference on Industrial Engineering and Engineering Management 2014; Atlantis Press: Paris, France, 2015.

18. Yao, X.; Lan, Q.; Wang, P. Initial Analysis on the Construction of Smart Governance System for Special Equipment Safety. In Proceedings of the 2017 International Conference on Smart City and Systems Engineering (ICSCSE), Changsha, China, 11-12 November 2017; IEEE: Piscataway, NJ, USA, 2017.

19. Christian, C. Architecture of the hyperledger blockchain fabric. Workshop Distrib. Cryptocurrencies Consens. Ledgers 2016, 310, 15718952.

20. Ge, L.; Brewster, C.; Spek, J.; Smeenk, A.; Top, J.; Van Diepen, F.; Klaase, B.; Graumans, C.; De Wildt, M.D.R. Blockchain for Agriculture and Food: Findings from the Pilot Study; Wageningen Economic Research, Wageningen University \& Research: Wageningen, The Netherlands, 2017.

21. Bumblauskas, D.; Mann, A.; Dugan, B.; Rittmer, J. A blockchain use case in food distribution: Do you know where your food has been? Int. J. Inf. Manag. 2020, 52, 102008. [CrossRef]

22. Lucena, P.; Binotto, A.P.D.; Momo, F.D.S.; Kim, H. A case study for grain quality assurance tracking based on a Blockchain business network. arXiv 2018, arXiv:1803.07877.

23. Liu, Q.; Guan, Q.; Yang, X.; Zhu, H.; Green, G.; Yin, S. Education-Industry Cooperative System Based on Blockchain. In Proceedings of the 2018 1st IEEE International Conference on Hot Information-Centric Networking (HotICN), Shenzhen, China, 15-17 August 2018; IEEE: Piscataway, NJ, USA, 2018.

24. Wang, S.; Taha, A.F.; Wang, J.; Kvaternik, K.; Hahn, A. Energy crowdsourcing and peer-to-peer energy trading in blockchain-enabled smart grids. IEEE Trans. Syst. Man Cybern. Syst. 2019, 49, 1612-1623. [CrossRef]

25. Kodali, R.K.; Yerroju, S.; Yogi, B.Y.K. Blockchain Based Energy Trading. In Proceedings of the TENCON 2018-2018 IEEE Region 10 Conference, Jeju, Korea, 28-31 October 2018; IEEE: Piscataway, NJ, USA, 2018; pp. 1778-1783.

26. Seungeun, K.; Kim, D. Design of an innovative blood cold chain management system using blockchain technologies. ICIC Express Lett. B Appl. Int. J. Res. Surv. 2018, 9, 1067-1073.

27. Bryatov, S.R.; Borodinov, A.A. Blockchain technology in the pharmaceutical supply chain: Researching a business model based on Hyperledger Fabric. In Proceedings of the International Conference on Information Technology and Nanotechnology (ITNT), Samara, Russia, 21-24 May 2019.

28. Ariffin, N.; Ismail, A.Z. The Design and Implementation of Trade Finance Application based on Hyperledger Fabric Permissioned Blockchain Platform. In Proceedings of the 2019 International Seminar on Research of Information Technology and Intelligent Systems (ISRITI), Yogyakarta, Indonesia, 5-6 December 2019; IEEE: Piscataway, NJ, USA, 2019.

29. Ma, C.; Kong, X.; Lan, Q.; Zhou, Z. The privacy protection mechanism of Hyperledger Fabric and its application in supply chain finance. Cybersecurity 2019, 2, 1-9. [CrossRef]

30. Lidong, N.; Kai, W. Research on Safety Supervision Model of Shanxi Group Coal Enterprises. Procedia Eng. 2012, 43, 499-505. [CrossRef]

31. Liu, Q.; Dou, F.; Meng, X. Building risk precontrol management systems for safety in China's underground coal mines. Resour. Policy 2020, 101631. [CrossRef]

32. Chen, H.; Chen, F.; Zhu, D.; Qi, H.; Long, R. Burnout in Chinese coal mine safety supervision. Energy Policy 2015, 85, 22-31. [CrossRef]

33. Zhang, Y.; Fu, G.; Zhao, Z.; Huang, Z.; Li, H.; Yang, J. Discussion on application of IOT technology in coal mine safety supervision. Procedia Eng. 2012, 43, 233-237. 
34. Reniers, G.; Ale, B.; Dullaert, W.E.; Soudan, K. Designing continuous safety improvement within chemical industrial areas. Saf. Sci. 2009, 47, 578-590. [CrossRef]

35. Bellamy, L.J.; Geyer, T.; Wilkinson, J. Development of a functional model which integrates human factors, safety management systems and wider organisational issues. Saf. Sci. 2008, 46, 461-492. [CrossRef]

36. McDonald, N.; Corrigan, S.; Daly, C.; Cromie, S. Safety management systems and safety culture in aircraft maintenance organisations. Saf. Sci. 2000, 34, 151-176. [CrossRef]

37. Kong, J. Discussion on Safety Management Mode of Special Equipment. Master's Thesis, Department of Public Administration, Nanchang University, Nanchang, China, 2010.

38. Liu, S. Analysis on the Reform of Special Equipment Inspection System. J. Macro Qual. Res. 2013, 2, $29-35$.

39. Liang, X.; Wang, X.; Wang, F.; Zhang, J. Graded and Classified Safety Management for Elevator Users Based on the Coordination Theory. In Proceedings of the Eighth International Conference on Management Science and Engineering Management; Springer: Berlin/Heidelberg, Germany, 2014.

40. Hao, S.; Jiang, S.; Ding, R. Research on Classified Regulations of Risk-oriented Special Equipment Users. Ind. Saf. Environ. Prot. 2013, 39, 31-33.

41. China Quality Daily. Special Equipment Accident Report and Investigation Regulation. 20 November 2019. Available online: http://m.cqn.com.cn/zj/content/2019-11/20/content_7800031.htm (accessed on 19 October 2020).

42. Yao, J.; Hu, L.; Wu, S. Application design of special equipment traceability system. China Equip. Eng. 2019, 21, 167-168.

43. $\mathrm{Xu}, \mathrm{P}$. Research on supervision issues under the background of socialization of special equipment inspection. Master's Thesis, Department of Public Administration, Shandong Normal University, Jinan, Shandong, China, 2018.

44. State Administration for Market Regulation. Report on the Management Regulation of Special Equipment Inspection Agencies; State Administration for Market Regulation: Beijing, China, 2003. Available online: http://www.chinalawedu.com/falvfagui/fg22016/42137.shtml (accessed on 8 August 2003).

45. Wang, R. Building a comprehensive information management system for special equipment inspection institutions. China Spec. Equip. Saf. 2006, 22, 2-6.

46. Ruan, H. Study on the Government Supervision of Special Equipment Safety in M City. Master's Thesis, Department of Public Administration, South China University of Technology, Guangzhou, China, 2014.

47. Cheng, X.; Zhou, S. Data management of special equipment safety supervision system. Qual. Technol. Superv. Res. 2019, 64, 55-57.

48. Farshidi, S.; Jansen, S.; Espana, S.; Verkleij, J. Decision Support for Blockchain Platform Selection: Three Industry Case Studies. IEEE Trans. Eng. Manag. 2020, 76, 1109-1128. [CrossRef]

49. Verkleij, J.R.Q. A Decision Support System for Blockchain Platform Selection. Master's Thesis, Department of Information and Communication Sciences, Utrecht University, Utrecht, The Netherlands, 2018.

50. Androulaki, E.; Barger, A.; Bortnikov, V.; Cachin, C.; Christidis, K.; De Caro, A.; Enyeart, D.; Ferris, C.; Laventman, G.; Manevich, Y.; et al. Hyperledger fabric: A distributed operating system for permissioned blockchains. In Proceedings of the Thirteenth EuroSys Conference, Porto, Portugal, 23-26 April 2018.

51. State Administration for Market Regulation. Special Equipment Safety Supervision Regulations; State Administration for Market Regulation: Beijing, China, 2008. Available online: http://www.gov.cn/zhengce/ content/2008-03/28/content_4470.htm (accessed on 3 August 2008).

Publisher's Note: MDPI stays neutral with regard to jurisdictional claims in published maps and institutional affiliations.

(C) 2020 by the authors. Licensee MDPI, Basel, Switzerland. This article is an open access article distributed under the terms and conditions of the Creative Commons Attribution (CC BY) license (http://creativecommons.org/licenses/by/4.0/). 